\title{
Heterogeneous Scarring Effects of Full-Year Non-employment*
}

\author{
Fatih Guvenen \\ Fatih Karahan \\ Serdar Ozkan \\ Jae Song
}

\section{A Web Appendix}

\section{A.1 Fraction of Workers Recovered Past Income}

In this section we plots the differences in fraction of workers whose incomes are above their past income $\bar{Y}_{t-1}^{i}$ between the treatment and control groups after 1, 2, 3, 5, and 10 years for prime age males (ages 35 to 50) (figure A.1a) and young workers (ages 25 to 34) (figure A.1b) across the recent earnings distribution.

Figure A.1 - Fraction of Workers Above Their Past Income After $t+k$ Years

(A) Prime Age Workers

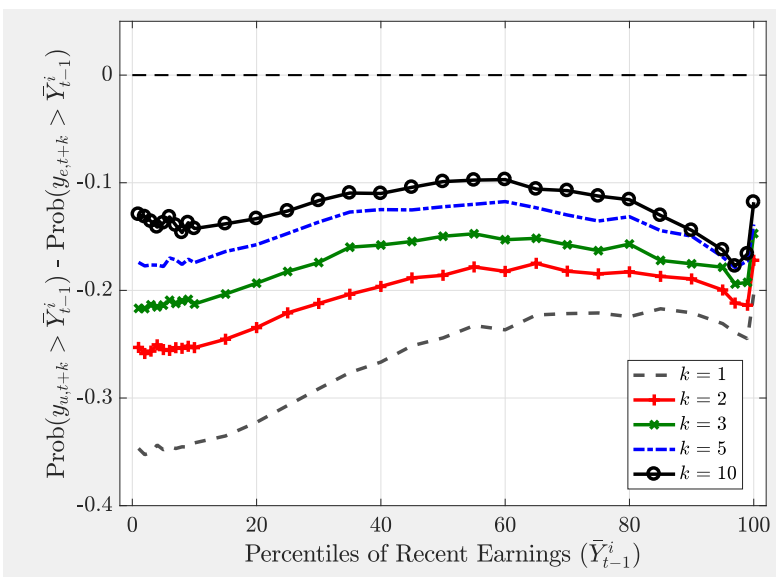

(B) Young Workers

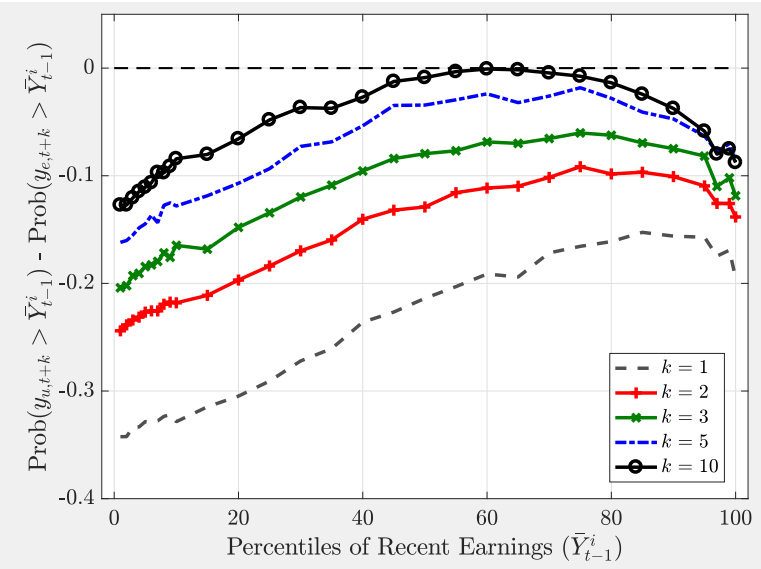

* Guvenen: Department of Economics, University of Minnesota, 4-101 Hanson Hall, 1925 S Fourth Street, Minneapolis, MN 55455, and NBER (e-mail: guvenen@umn.edu). Karahan: Federal Reserve Bank of New York, 33 Liberty St New York, NY 10045 (Fatih.Karahan@ny.frb.org). Ozkan: University of Toronto, Max Gluskin House 150 St. George St. Toronto, ON Canada M5S 3G7. Song: Social Security Administration, 5107 Leesburg Pike, Suite 1400 Falls Church, VA 22041 (jae.song@ssa.gov). The views expressed herein are those of the authors and do not represent those of the Social Security Administration or the Federal Reserve Banks of Minneapolis and New York. Guvenen acknowledges financial support from the National Science Foundation (SESâ1357874). 


\section{A.2 Scarring Effects for Young Workers}

Throughout the main text, we showed the scarring effects of full-year non-employment for prime age workers. This section shows analogous outcomes for young workers (ages 25 to 34$)$.

Figure A.2 - Average Earnings Losses

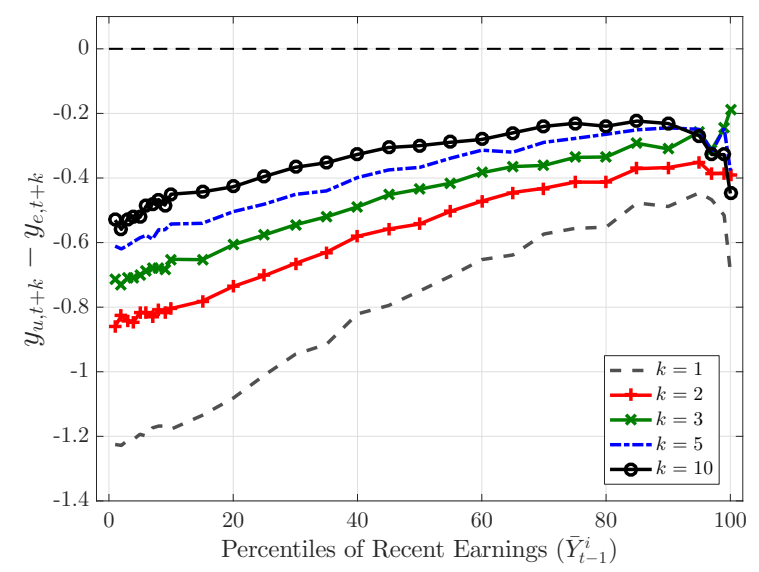

Figure A.3 - Intensive and Extensive Margins

(A) Intensive margin

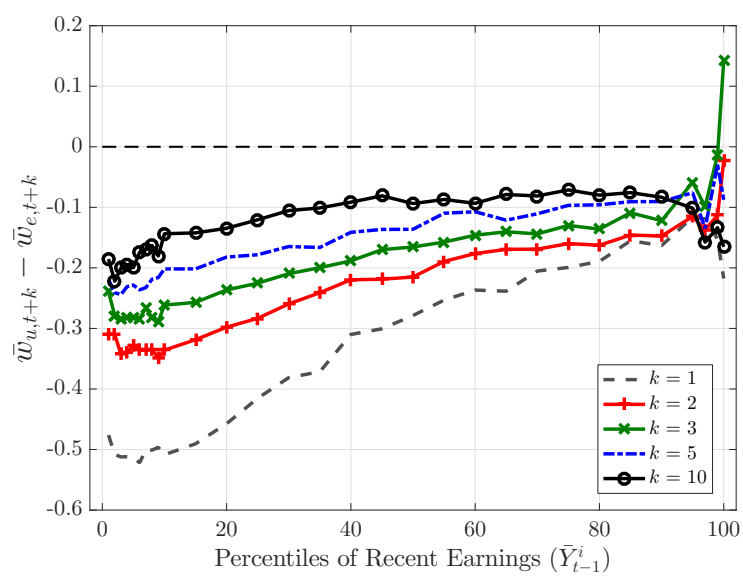

(B) Extensive margin

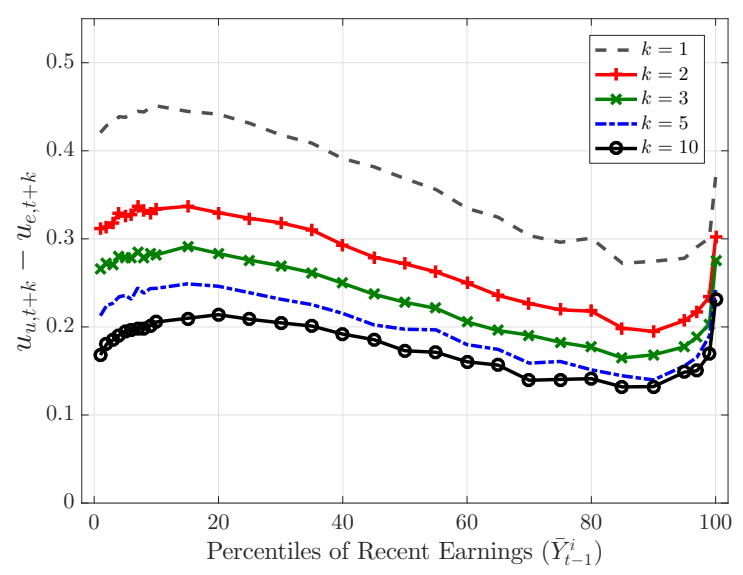




\section{A.3 Scarring Effects Conditional on Past 10-Year Income}

Throughout the main text, we showed the scarring effects of full-year non-employment condition on average past 5 -year income between $t-1$ and $t-5, \bar{Y}_{t-1}^{i}$. This section shows analogous outcomes conditional on average past 10-year income between $t-1$ and $t-10$.

Figure A.4 - Average Earnings Losses

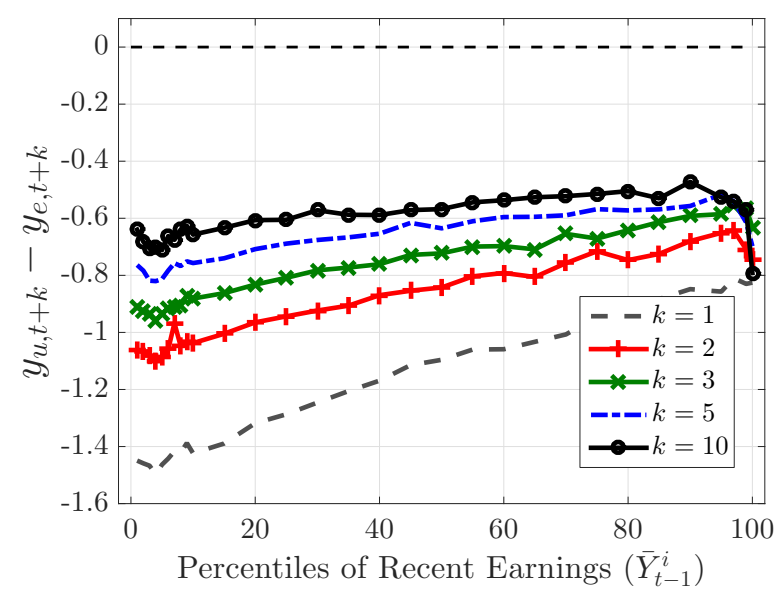

FiguRE A.5 - Intensive and Extensive Margins

(A) Intensive margin

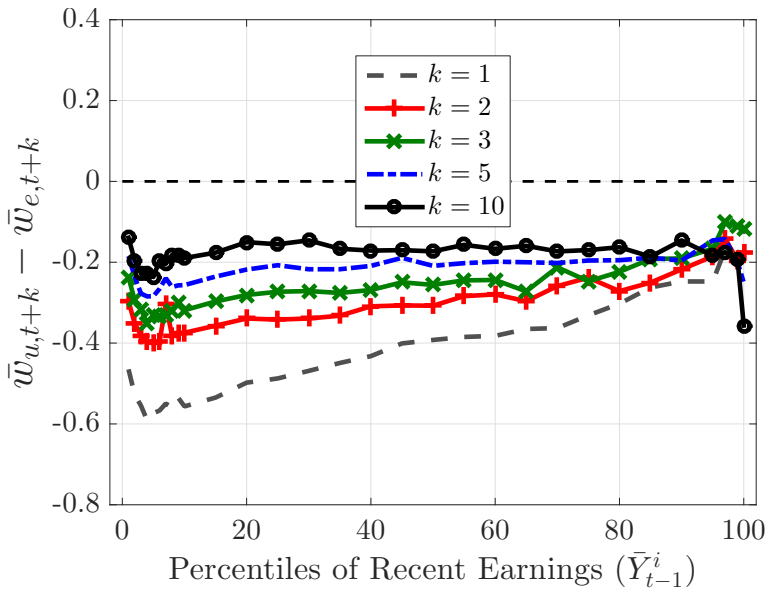

(B) Extensive margin

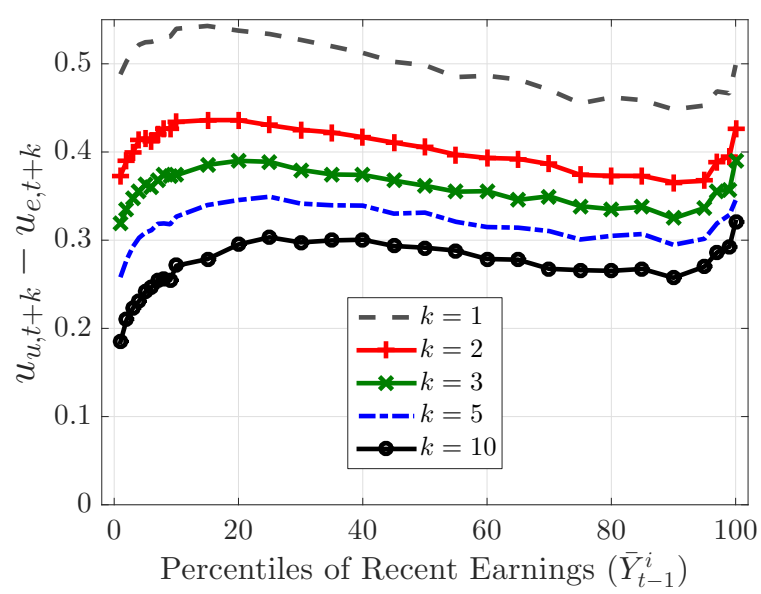

